\title{
Staphylococcus gallinarum
}

National Cancer Institute

\section{Source}

National Cancer Institute. Staphylococcus gallinarum. NCI Thesaurus. Code C86760.

A species of facultatively anaerobic, Gram positive, cocci shaped bacteria in the phylum Firmicutes. This species is positive for catalase, phosphatase and caseinase and negative for coagulase and oxidase. It can ferment arabinose, cellobiose, fructose, galactose, glycerol, maltose, mannitol, mannose, ribose, sucrose, trehalose, turanose, and xylose but not rhamnose or fucose. S. gallinarum is a commensal organism in poultry and goats, where it can cause opportunistic infections, and is rarely a human pathogen. 